\title{
Da educação eurocêntrica à educação antirracista: uma introdução
}

\section{From eurocentric education to anti-racist education: an introduction}

\author{
Maurício Silva \\ Doutor \\ Universidade Nove de Julho - UNINOVE. \\ São Paulo, SP - Brasil. \\ maurisil@gmail.com
}

Resumo: O presente artigo busca discutir os encontros e tensões entre a educação eurocêntrica e a educação antirracista no contexto educacional brasileiro, a fim de observarmos não somente o alcance do racismo institucionalizado, mas também os desdobramentos práticos e simbólicos de uma ação e um discurso educativos pautados em processos diversos de silenciamento e invisibilização do próprio racismo.

Palavras chave: educação eurocêntrica; educação antirracista; racismo institucionalizado; educação brasileira

Abstract: This article aims to discuss the encounters and tensions between Eurocentric education and antiracist education in the Brazilian educational context, in order to observe not only the scope of institutionalized racism, but also the practical and symbolic consequences of an educational action and discourse based on diverse processes of silencing and making racism itself invisible.

Key-words: eurocentric education; anti-racist education; institutionalized racism; Brazilian education.

Cite como

(ABNT NBR 6023:2018)

SILVA, Maurício. Da educação eurocêntrica à educação antirracista: uma introdução. Dialogia, São Paulo, n. 38, p. 1-10, e20213, maio/ago. 2021. Disponível em: https://doi.org/10.5585/38.2021.20213.

American Psychological Association (APA)

Silva, M. (2021, maio/ago.). Da educação eurocêntrica à educação antirracista: uma introdução. Dialogia, São Paulo, 38, p. 1-10, e20213. https://doi.org/10.5585/38.2021.20213. 


\section{Introdução}

A intersecção entre o dilatado universo da educação e as relações étnico-raciais tem-se mostrado, particularmente no Brasil, bastante promissora, sobretudo após a promulgação da lei 10639/03, que veio dar novo impulso às pesquisas acerca da participação da população afrodescendente na sociedade brasileira, fazendo, entre avanços e retrocessos, com que o tema entrasse na agenda política do país e se tornasse um dos assuntos mais debatidos ultimamente, muito em razão de sua capilaridade com outros temas afins, como o racismo, a discriminação, a inclusão social e educacional e o empoderamento da população negra. O Brasil, como se sabe, é um país pródigo em práticas excludentes e discriminatórias, realidade confirmada pelas próprias estatísticas, que nos apresentam um quadro alarmante de diferenças em todos os âmbitos da sociedade. Nesse jogo de aparências sociais, em que ficamos numa incômoda situação de quem se posiciona, psicologicamente falando, entre a parataxia e o bovarismo, imperam ora o preconceito (esse julgamento prévio, feito sem ponderação ou conhecimento dos fatos e ligado a um comportamento de inflexibilidade e de dogmatismo), ora a discriminação (atitude ligada ao ato de separar as pessoas de origens étnico-raciais diferentes), ora ainda o próprio racismo (a rigor, a teoria que defende a superioridade de certas raças em relação a outras), nas definições de Zilá Bernd (1994).

Essa realidade se reproduz, evidentemente, em diferentes ambientes e espaços, sejam eles institucionais ou não, como é o caso da escola, onde a discriminação racial é um fato há muito constatado (SILVA JÚNIOR, 2002; CARVALHO, 2012; LIMA, 2015). A questão da discriminação racial nas escolas, além disso, tem-se revelado demasiadamente complexa, já que se encontra disseminada nos três âmbitos fundamentais que compõem a estrutura escolar, tornando a própria discriminação - cuja gênese encontra-se, é verdade, em determinadas conjunturas históricas - num problema estrutural: no âmbito da gestão administrativa, a discriminação se reflete numa cadeia que nasce no modo muitas vezes autoritário como a escola é gerida, em que a instância dos colegiados é subjugada pelo poder centralizador do corpo gestor; no âmbito pedagógico, ela se traduz numa prática pedagógica, adotada no ambiente escolar, que incide, fundamentalmente, sobre os três vetores em que compreende a dinâmica ensino-aprendizagem: o currículo, a avaliação e a prática docente, instância em que reside o campo mais sensível à disseminação de atitudes racistas; finalmente, no âmbito político-social, a discriminação se desdobra em atitudes que se situam na interface escola-sociedade, tornando-se, por sua vez, mais um universo fértil de atitudes discriminatórias. 
Avaliar, portanto, a questão da discriminação na escola - esse autêntico subproduto da categoria-gênese de racismo institucional - torna-se um exercício que tem seu vértice no encontro desses três âmbitos, apontando para a necessidade de se apoiar, na prática cotidiana, uma educação e uma pedagogia antirracistas (LIMA e SOUSA, 2014; GOMES, 2017).

O presente artigo busca discutir os encontros e tensões entre a educação eurocêntrica e a educação antirracista no contexto educacional brasileiro, a fim de observarmos não somente o alcance do que acabamos de chamar, aqui, de racismo institucionalizado, mas também os desdobramentos práticos e simbólicos de uma ação e um discurso educativos pautados em processos diversos de silenciamento e invisibilização do próprio racismo, o que certamente resulta, entre outras coisas, em sua inaceitável naturalização. Adota-se, para tanto, um recorte metodológico qualitativo e de pesquisa bibliografia, sem se avançar numa perspectiva mais profunda do tema, exatamente por se tratar de uma abordagem introdutória.

\section{Da educação eurocêntrica à educação antirracista}

Escrevendo uma espécie de editorial para o jornal paulistano $O$ Alfinete, periódico dedicado aos homens de cor, um jornalista autonomeado Oliveira (1918, p. 1) critica, na edição de setembro de 1918, a falta de consciência dos negros acerca da necessidade de se alfabetizarem: após dizer que os negros brasileiros vivem "com o pensamento accorrentado" (p. 1), sem impor nenhuma questão de ordem intelectual ou social, completa defendendo sua alfabetização, para que não se transformem em "servos voluntarios".

Passado um século dessa diatribe, não se pode dizer que a situação do negro brasileiro continue a mesma, sobretudo no que compete a sua alfabetização, mas, apesar dos muitos avanços verificados nas últimas décadas, o que se constata é que há ainda um longo caminho a ser percorrido, até que se possa falar em escolarização plena desse contingente populacional. Muitas das conquistas alcançadas nessa área devem-se, é certo, ao empenho da sociedade civil, sobretudo por meio dos movimentos negros (PEREIRA, 2013; SANTOS, 2005), responsáveis por impulsionar a aprovação de leis especialmente preocupadas em suprir demandas educacionais da população afrodescendente no Brasil, como é o caso da já bastante debatida lei 10639, de 2003. Associada ao Parecer (2003) e à Resolução (2004) do Conselho Nacional de Educação, a referida lei determina e aponta diretrizes para a implementação, no currículo do Ensino Fundamental e Médio, do ensino de História e Cultura Afro-Brasileira e Africana, alterando a norma maior que rege nossa educação, a Lei de Diretrizes e Base da Educação Nacional (1996). 
Não se trata, como pode parecer, de uma lei de alcance limitado, de natureza "curricular" ou afim, mas um dispositivo que assume como efeito colateral profícuo, por um lado, a desconstrução de um imaginário estereotipado em relação à cultura afro-brasileira e a afirmação identitária do afrodescendente e, por outro lado, a divulgação de episódios históricos e ideologias de cunho discriminatório, acerca da história da África e dos africanos em situação de diáspora. Como lembra Luciano Costa (2010, p. 23), "a lei [10639/03] traz uma nova oportunidade para os afrodescendentes, no sentido de desconstruir um imaginário e construir uma nova mentalidade com relação à cultura negra no Brasil". Portanto, em vigência há mais de dez anos, ela acabou por dar novo impulso às pesquisas acerca da participação da população afrodescendente na sociedade brasileira, em especial no campo da educação e seus inúmeros desdobramentos; com efeito, como afirmam Iolanda de Oliveira, Petronilha Gonçalves Silva e Regina Pahim Pinto (2005, p. 231), ao tratarem da aplicação da lei 10639/03 na escola, em texto publicado logo após sua promulgação,

“o esclarecimento sobre a construção histórica das relações sociais, especialmente na
educação das crianças e adolescentes, é uma medida preventiva fundamental contra a
permanência das estruturas sociais e culturais que dão sustentação a todas as formas de
intolerância, de xenofobia, de discriminação e de racismo".

Essa é, de fato, uma ação que, no conjunto, busca desfazer os equívocos que, tradicionalmente, tem-se alastrado no ambiente escolar, acerca da história e da cultura brasileiras, em especial no que compete ao legado cultural africano que aqui chegou, primeiro, por meio das populações escravizadas e, depois, por meio de fluxos migratórios voluntários ou compulsórios. Grosso modo, trata-se de uma visão distorcida de nossa própria história - bem como da história do continente africano e sua importância para a constituição de nossa cultura -, numa abordagem acadêmica e escolar que vai da deturpação e do alienamento à simples acriticidade (AZEVÊDO, 1987; SANSONE, 2002).

Do ponto de vista normativo, há ainda, nesse mesmo universo, a aprovação de uma legislação destinada à valorização do negro na conjuntura da educação superior, que passa pela aprovação de ações afirmativas - nesse contexto, política que promove o acesso à e/ou permanência de grupos estigmatizados em uma instituição de ensino superior, objetivando sua democratização (GUIMARÃES, 2008; SILVA, 2003; GOMES, 2003) -, como é o caso das chamadas cotas raciais, cujo alcance vai muito além do expediente de ingresso no ensino superior (SANTOS, 2006; MUNANGA, 2006). Como lembram Adailton Silva et alii (2009, p. 58), 
“destacando a situação de absoluta diferenciação entre negros e brancos e reconhecendo o passado e o presente de discriminação racial, as cotas destacam-se como instrumento de enfrentamento da desigualdade racial no país. Não o único, mas um importante instrumento de equalização de oportunidades, em um contexto histórico em que mesmo o Estado brasileiro foi ator relevante na construção das desigualdades raciais".

Toda essa legislação não faria sentido algum, não fosse a compreensão do ambiente escolar - aqui entendido como um conjunto de métodos, teorizações e procedimentos, voltado à dinâmica do ensino-aprendizagem no processo de escolarização formal - como um espaço multicultural, na acepção de uma prática educativa que "propõe a reforma das escolas e de outras instituições educacionais com a finalidade de criar iguais oportunidades de sucesso escolar para todos os alunos independentemente de seu grupo social, étnico-racial" (GONÇALVES e GONÇALVES E SILVA, 2006, p. 50). Ainda que se conteste, em tese, a ideia mais genérica de multiculturalismo como um conceito historicamente marcado, relacionado, em sua origem, com um projeto de colonização que, no limite, subjuga e suprime traços identitários (TAVARES e GOMES, 2018), não se deve subestimar sua capacidade - como princípio operatório, dentro do contexto tensionado da educação escolar - de atuar no sentido de reconhecer e, até certo ponto, promover a coexistência de valores, sensibilidades, ideários, representações e identidades distintas, o que, nas circunstâncias históricas vividas pela população afrodescendente brasileira na atualidade, representa um significativo avanço em direção não apenas à estabilização das relações sociais, mas, sobretudo, ao reconhecimento e valorização do legado sociocultural africano.

Essa tem sido uma demanda histórica dos povos africanos em situação de diáspora, aqui como em outros continentes. Nos Estados Unidos, por exemplo, em sua conhecida Declaration of the Rights of the Negro Peoples of the World (1920), Marcus Garvey (2004, p. 20) já protestava contra a separação de escolas para brancos e negros e, de modo geral, requisitava a inclusão do ensino da bistória do negro nos currículos escolares, contra "the system of education in any country where Negroes are denied the same privileges and advantages as other races".

O currículo, aliás, é um aspecto central da discussão acerca da interface entre educação e questões étnico-raciais. É a ausência quase completa da temática racial no currículo escolar, em todos os níveis do processo de escolarização, que tem levado à defesa incontornável ora de um currículo multicultural - para nos mantermos no âmbito da discussão acima engendrada -, ora de um currículo afrocentrado.

Sobre a defesa de um currículo multicultural, sua adesão nasce da constatação de que é no campo curricular que as tensões raciais adquirem uma de suas expressões máximas, na medida em que refletem o ideário de grupos raciais dominantes e se manifestam como narrativas com alto grau de racialização. Como lembra Vanessa Oliveira (2003), ao tratar da relação do currículo com 
questões de afrodescendência, "pelas narrativas curriculares, identidades hegemônicas são formadas e fixadas, tanto quanto são questionadas, contestadas e disputadas" (OLIVEIRA, 2003, p. 105). Ademais, há que se observar que a promulgação da lei 10639/03 não redundou, necessariamente, na apropriação de diretrizes para a implantação de um currículo multicultural, como revela a pesquisa levada a cabo por Denise Lima e Carlos Sousa (2014). Mais importante para os propósitos deste artigo, contudo, parece-nos ser a proposição de um currículo afrocentrado, isto é, aquele que contem em si valores culturais africanos e afro-brasileiros, tal como prevê a lei 10639, de 2003. Cumpre ressaltar, contudo, que ambas as "modalidades" curriculares multicultural e afrocentrado - referem-se e procuram se afirmar como contraponto ao conceito de eurocentrismo, responsável por muitas das contradições e das incongruências, das distorções e das anomalias, das desordens e dos desconcertos, enfim de boa parte das tensões que marcam as relações étnico-raciais no contexto escolar. Desse modo, trata-se de narrativas e práticas curriculares que adquire, no contexto escolar a que se vincula, um claro e deliberado sentido de resistência.

O conceito de eurocentrismo não é novo, tampouco se trata de uma categoria histórica semanticamente estabilizada; ao contrário, sua plurissignificância torna seu emprego extremamente comprometedor e arriscado, caso não sejam feitas as devidas ressalvas quanto ao contexto e ao sentido que se lhe queira dar. De qualquer maneira, tem sido vastamente utilizado nas discussões acerca dos currículos escolares, especialmente no sentido de exprimir um ponto de vista unilateral, tendencioso e arbitrário, por privilegiar uma mundividência e uma subjetividade europeias, que, ao se afirmar como racionalidade de valor universal, desqualifica outras experiências e saberes que, afinal, compõem o complexo universo da educação escolarizada. Por se tratar de uma formulação que exprime uma perspectiva discricionária, o eurocentrismo torna-se objeto de crítica recorrente no discurso acadêmico, sobretudo a partir da segunda metade do século XX (embora já viesse sendo discutido por pensadores e teóricos brasileiros antes disso), com o avanço dos Estudos Culturais, Pós-Coloniais, Subalternos, Decoloniais e afins. Essa crítica já estava presente na década de setenta, quando Edward Said publica seu célebre Orientalismo (1978), ao lembrar que aquele conceito resulta da hegemonia cultural europeia, desdobrando-se na "idea of European identity as a superior one in comparasion with all the non-European peoples and cultures" (SAID, 1979, p. 7). No âmbito dos Estudos Decoloniais, o conceito ganha uma definição mais precisa e, porventura, mais operacional: 


\begin{abstract}
"Eurocentrismo é, aqui, o nome de uma perspectiva de conhecimento cuja elaboração sistemática começou na Europa Ocidental antes de meados do século XVII, ainda que algumas de suas raízes são sem dúvida mais velhas, ou mesmo antigas, e que nos séculos seguintes se tornou mundialmente hegemônica percorrendo o mesmo fluxo do domínio da Europa burguesa. Sua constituição ocorreu associada à específica secularização burguesa do pensamento europeu e à experiência e às necessidades do padrão mundial de poder capitalista, colonial/moderno, eurocentrado, estabelecido a partir da América (...). Não se trata, em consequência, de uma categoria que implica toda a história cognoscitiva em toda a Europa, nem na Europa Ocidental em particular. Em outras palavras, não se refere a todos os modos de conhecer de todos os europeus e em todas as épocas, mas a uma específica racionalidade ou perspectiva de conhecimento que se torna mundialmente hegemônica colonizando e sobrepondo-se a todas as demais, prévias ou diferentes, e a seus respectivos saberes concretos, tanto na Europa como no resto do mundo" (QUIJANO, 2005, p. 239).
\end{abstract}

Embora um pouco extensa, a citação revela exatamente esse aspecto unidireccional - e, portanto, totalitário - do conceito, que, muitas vezes, redunda em práticas elusivas de comunitarismo epistémico - reprovadas, por Boaventura Santos (2018, p. 25), como um "pensamiento crítico eurocêntrico" demasiadamente resiliente -, as quais escondem seu caráter, a um só tempo, opressor e dominante.

É, com efeito, o que costuma acontecer com o currículo, quando confrontado com a questão étnico-racial brasileira. De modo geral e dentro dos limites em que isso é possível, o currículo eurocentrado é um dos responsáveis pela propagação e perpetuação de uma "ideologia" racista, que se traduz em práticas discriminatórias na escola. Nelson Piletti e Walter Praxedes (2010, p. 134), por exemplo, tratando da questão racial na educação escolar, lembram que, mesmo entre os alunos de baixa renda, os negros apresentam maior índice de insatisfação escolar, o que indica que o problema educacional relacionado aos negros não é apenas uma questão de exclusão social; o maior problema, afirmam os autores, é que nossa cultura está centrada nos modelos europeus:

\footnotetext{
"o eurocentrismo é um dos grandes obstáculos que devem ser superados para que sejam assegurados o acesso e a permanência dos diversos grupos étnico-raciais no sistema escolar brasileiro, uma reivindicação política e educacional dos grupos sociais marginalizados".
}

O fato é que a escola brasileira parece não ter aprendido, ainda, a conviver com a formação cultural multirracial e pluriétnica de seu alunado, privilegiando o currículo de matriz europeia, ou seja, baseada em uma "visão monocultural e eurocêntrica” (FERNANDES, 2005, p. 380).

\title{
Considerações finais
}

Uma vez inseridas as informações relativas ao universo cultural afro-brasileiro na escola, como reza a lei 10639/03, o preconceito de natureza racial - relacionado a estruturas reais ou 
imaginárias, mas, sobretudo, simbólicas - tende a ser, se não rompido, minimizado. É preciso considerar, contudo, que o Brasil - como, de resto, a quase totalidade dos países do chamado Terceiro Mundo - foi vítima de um longo processo de colonização que, baseado numa espécie de naturalização da violência epistêmica que se retroalimenta permanentemente, acabou por criar um trauma colonial, tornando o negro uma espécie contemporânea de pária social.

Nesse contexto, o conceito de ambiciona ocupar na sociedade não um espaço hegemônico, mas se afirmar como uma razão epistemológica que possa, autonomamente, contribuir para a solução da atual "crise" étnica que se verifica entre nós, distinguindo-se como categoria fundamental de uma ampla e complexa razãa africana, que segue um modelo epistemológico assentado tanto numa práxis quanto numa gnosiologia africanas. Evidentemente, não se deve entender o epíteto africano, aqui empregado, de um ponto de vista meramente topológico, menos ainda essencialista, mas numa acepção plurissignificativa, que inclui as diásporas e as influências culturais, as práticas de resistência às teorias raciais e às políticas de exclusão, as ações públicas e os discursos históricos e muito mais... No fundo, o que se deve buscar, ao se defender o conceito e a prática afrocêntricas, é tornar os valores culturais de matriz africana um dos vetores pedagógicos em diálogo com os demais valores que compõem o saber "universal". Em suma, em vez de centralizar o processo educacional a partir de uma matriz cultural específica, dever-se-ia fazer um esforço no sentido de descentralizar os saberes, de modo a romper o paradigma da hegemonia cultural assumida por determinadas culturas, em especial a europeia. O resultado seria, obviamente, um diálogo profícuo e pluralista entre os múltiplos saberes, numa relação que, sem ser hierárquica e contingencial, é, antes de mais nada, estruturalmente igualitária. Trata-se, nesse sentido, mais do que um movimento de repercussão "apenas" no âmbito educacional, de uma dinâmica de amplo alcance político, na medida em que pressupõe a descolonização dos saberes, no universo da cultura e das práticas sociais. Afinal de contas, a questão racial é particularmente complexa, não devendo ser, como alerta Michael Apple (2017), homogeneizada.

\section{Referências}

APPLE, Michael W. A educação pode mudar a sociedade? Petrópolis, Vozes, 2017.

AZEVÊDO, Eliane. Raça. Conceito e Preconceito. São Paulo, Ática, 1987.

BERND, Zilá. Racismo e Anti-racismo. São Paulo, Moderna, 1994.

CARVALHO, Marília Pinto de (org.). Diferenças e desigualdades na escola. São Paulo, Papirus, 2012. 
COSTA, Luciano Gonsalves (org.). História e cultura afro-brasileira. Subsidios para a prática da educação sobre relaçôes étnico-raciais. Maringá, EDUEM, 2010.

FERNANDES, José Ricardo. "Ensino de História e Diversidade Cultural: Desafios e Possibilidades”. Caderno Cedes, Campinas, Vol. 25, No. 67: 378-388, set.-dez. 2005.

GARVEY, Marcus. Selected Writings and Speeches of Marcus Garvey. Ed. Bob Blaisdell, New York, Dover, 2004.

GOMES, Joaquim Barbosa. "O debate constitucional sobre as ações afirmativas". In: SANTOS, Renato Emerson dos; LOBATO, Fátima (orgs.). Ações Afirmativas. Políticas Públicas contra as Desigualdades Sociais. Rio de Janeiro, DP\&A, 2003, p. 15-57.

GOMES, Nilma Lino. O movimento negro educador. Saberes construidos nas lutas por emancipação. Petrópolis, Vozes, 2017.

GONÇALVES, Luiz Alberto Oliveira; GONÇALVES E SILVA, Petronilha Beatriz. O jogo da diferença. O multiculturalismo e seus contextos. Belo Horizonte, Autêntica, 2006.

GUIMARÃES, Antonio Sérgio Alfredo. Preconceito racial: modos, temas e tempos. São Paulo, Cortez, 2008.

LIMA, Denise Maria Soares; e SOUSA, Carlos Ângelo de Meneses. "Como os currículos escolares podem contribuir para uma política antirracista nas escolas". Dialogia, Universidade Nove de Julho, São Paulo, No. 20: 85-98, jul.-dez. 2014.

LIMA, Maria Nazaré de. Relações étnico-raciais na escola: o papel das linguagens. Salvador, EDUNEB, 2015.

MUNANGA, Kabengele. "Políticas de Ação Afirmativa em benefício da população negra no Brasil - um ponto de vista em defesa de cotas". In: GOMES, Nilma Lino; e MARTINS, Aracy Alves (orgs.). Afirmando Direitos. Acesso e Permanência de Jovens Negros na Universidade. Belo Horizonte, Autêntica, 2006, p. 47-59.

OLIVEIRA. "Aos nossos leitores". O Alfinete. Orgam Litterario, Critico e Recreativo, São Paulo, No. 2: $1,03 / 09 / 1918$.

OLIVEIRA, Iolanda de; SILVA, Petronilha Beatriz Gonçalves e; PINTO, Regina Pahim (orgs.). Negro e Educaşão: Escola, Identidades, Cultura e Políticas Públicas. São Paulo, Ação Educativa/ANPEd, 2005.

OLIVEIRA, Vanessa Regina Eleutério Miranda de. "Um Currículo Multicultural: Práticas Inclusivas e a Afro-Descendência". In: OLIVEIRA, Iolanda de; GONÇALVES E SILVA, Petronilha Beatriz (Orgs.). Identidade Negra. Pesquisas sobre o Negro e a Educação no Brasil. São Paulo/Rio de Janeiro, Ação Educativa/Anped, 2003, p. 103-116.

PEREIRA, Amílcar Araújo. O mundo negro. Relações Raciais e a constituição do movimento negro contemporâneo no Brasil. Rio de Janeiro, Pallas/Faperj, 2013.

PILETTI, Nelson; PRAXEDES, Walter. Sociologia da Educação. Do Positivismo aos Estudos Culturais. São Paulo, Ática, 2010. 
QUIJANO, Anibal. “Colonialidade do poder, eurocentrismo e América Latina”. In: LANDER, Edgardo (org).A colonialidade do saber: eurocentrismo e ciências sociais. Perspectivas latino-americanas. Buenos Aires, CLACSO, Colección Sur Sur, 2005, p.227-278.

SAID, Edward. Orientalism. New York, Vintage Books, 1979.

SANSONE, Livio. "Da África ao Afro: Uso e Abuso da África entre os Intelectuais e na Cultura Popular Brasileira durante o Século XX”. Afro-Ásia, Universidade Federal da Bahia, Salvador, No. 27: 249-269, 2002.

SANTOS, Boaventura de Sousa. "Introducción a las epistemologias del sur". MENESES, Maria Paulo; BIDASECA, Karina (orgs.). Epistemologías del Sur - Epistemologias do Sul. Buenos Aires/Coimbra, CLACSO/CES, 2018, p. 25-61.

SANTOS, Renato Emerson dos. "Redefinindo os termos do debate sobre a democratização da universidade: as experiências do Programa Políticas da Cor". In: GOMES, Nilma Lino; MARTINS, Aracy Alves (orgs.). Afirmando Direitos. Acesso e Permanênciade Jovens Negros na Universidade. Belo Horizonte, Autêntica, 2006, p. 17-31

SANTOS, Sales Augusto dos. "A lei 10.639/03 como fruto da luta anti-racista do Movimento Negro”. In: SECRETARIA DE EDUCAÇÃO CONTINUADA, ALFABETIZAÇÃO E DIVERSIDADE (org.). Educaşão anti-racista: caminhos abertos pela Lei Federal n. 10.639/03. Brasília, Secretaria de Educação Continuada, Alfabetização e Diversidade, 2005, p. 21-37.

SILVA, Adailton; LUIZ, Cristiana; JACCOUD, Luciana; SILVA, Waldemir. "Entre o racismo e a desigualdade: da construção à promoção de uma política de igualdade racial (1988-2008)". In: JACCOUD, Luciana (org.). A construção de uma política de promoção da igualdade racial: uma análise dos últimos 20 anos. Brasília, IPEA, 2009, p. 19-92.

SILVA, Cidinha da. "Ações afirmativas em educação: um debate para além das cotas". In:

SILVA, Cidinha da (org.). Ações Afirmativas em Educação: Experiências Brasileiras. São Paulo, Summus, 2003, p. 17-38.

SILVA JÚNIOR, Hélio. Discriminação racial nas escolas: entre a lei e as práticas sociais. Brasília, UNESCO, 2002.

TAVARES, Manuel; GOMES, Sandra Rosa. "Multiculturalismo, interculturalismo e decolonialidade: prolegômenos a uma pedagogia decolonial". Dialogia, Universidade Nove de Julho, São Paulo, No. 29: 47-68, mai.-ago. 2018. 